\title{
Avaliação da acessibilidade em escolas municipais de Uberaba, $\mathbf{M G}^{\mathbf{1}}$
}

\author{
Victor Ruan Carvalho Soares ${ }^{\mathrm{a}}$, Alessandra Cavalcanti ${ }^{\mathrm{a}, \mathrm{b}}$, \\ Fabiana Caetano Martins Silva e Dutra ${ }^{\mathrm{b}, \mathrm{c}}$, Andrea Ruzzi-Pereira ${ }^{\mathrm{b}, \mathrm{d}}$
}

${ }^{a}$ Laboratório Integrado de Tecnologia Assistiva - LITA, Universidade Federal do Triângulo Mineiro - UFTM,

Uberaba, MG, Brasil

${ }^{\text {b} D e p a r t a m e n t o ~ d e ~ T e r a p i a ~ O c u p a c i o n a l, ~ U n i v e r s i d a d e ~ F e d e r a l ~ d o ~ T r i a ̂ n g u l o ~ M i n e i r o ~-~ U F T M, ~}$ Uberaba, MG, Brasil

'Núcleo de Estudos e Pesquisa em Trabalho, Saúde e Participação Social - NETRAS, Universidade

Federal do Triângulo Mineiro - UFTM, Uberaba, MG, Brasil

${ }^{` N}$ Núcleo de Estudos e Pesquisa em Saúde Mental, Álcool e outras Drogas - NEPSMAD, Universidade

Federal do Triângulo Mineiro - UFTM, Uberaba, MG, Brasil

\begin{abstract}
Resumo: Introdução: As barreiras arquitetônicas geram dificuldades, comprometem significativamente o acesso de pessoas a diferentes ambientes e limitam a acessibilidade. Na rede pública de ensino brasileira, essas questões se mostram mais relevantes quando se analisa o processo de inclusão escolar dos educandos com necessidades especiais para mobilidade. O processo de inclusão escolar é intrinsecamente interligado com a condição de acessibilidade da escola. Pelo Programa Escola Acessível, escolas têm recebido incentivo financeiro para adequação de seu espaço físico com relação à acessibilidade. Objetivo: Descrever a acessibilidade das escolas participantes do Programa Escola Acessível no município de Uberaba, MG, e identificar materiais adquiridos, adaptações e reformas implementadas, avaliando se as mudanças atendem à norma técnica de acessibilidade vigente e se estão de acordo com propostas recomendadas. Metodologia: Estudo exploratório-descritivo de natureza quantitativa, conduzido em dois momentos através de pesquisa documental e estudo de campo. Foram identificadas 11 escolas municipais que participaram do Programa Escola Acessível. Resultados: A maioria das escolas apresentou problemas em quase todos os itens avaliados (calçada, circulação interna, esquadrias, banheiros, vestiários, piscina, estacionamento, cinemas ou teatros, auditórios, estádios, ginásios de esporte, casas de espetáculos, salas de conferência e similares e mobiliário escolar). Conclusão: As escolas públicas avaliadas apresentam limitações quanto à acessibilidade, as barreiras físicas edificadas no passado não foram eliminadas e ainda são obstáculos a serem transpostos pelos alunos com necessidades especiais.
\end{abstract}

Palavras-chave: Terapia Ocupacional, Equipamentos de Auto-Ajuda, Estruturas de Acesso.

\section{Accessibility assessment in municipal schools of Uberaba, Minas Gerais state}

\begin{abstract}
Introduction: Architectural barriers generate difficulties, significantly impair people's access to different environments, and limit accessibility. In the Brazilian public school system, these questions become more relevant when the process of school inclusion of students with special needs for mobility is analyzed. The process of school inclusion is intrinsically associated with the accessibility condition of schools. Through the 'Accessible School Program', schools have received financial incentive to adapt their physical spaces according to accessibility. Objective: To describe the accessibility of the schools that have taken part in the 'Accessible School Program' in the municipality of Uberaba, Minas Gerais state. The study also aimed to identify the materials purchased and the adjustments and repairs implemented, evaluating whether the changes attend the technical standard of accessibility and agree with the recommended proposals. Methodology: This is an exploratory-descriptive study of quantitative nature; it was
\end{abstract}

Autor para correspondência: Alessandra Cavalcanti, Unidade Centro Educacional, Departamento de Terapia Ocupacional, Universidade Federal do Triângulo Mineiro, Av. Getúlio Guaritá, s/n, $3^{\circ}$ Piso, sala 329, CEP 38025-440, Uberaba, MG, Brasil, e-mail: lita@to.uftm.edu.br Recebido em Maio 14, 2013; $1^{\text {a }}$ Revisão em Jul. 11, 2013; $2^{\text {a }}$ Revisão em Nov. 14, 2013; Aceito em Dez. 11, 2013. 
conducted in two phases through documental research and field study. Eleven municipal schools that participated in the 'Accessible School Program' were identified. Results: Most of the schools presented problems in almost all the items evaluated: sidewalks, common inside area, door squares, restrooms, locker rooms, swimming pools, parking, cinemas or theatres, auditoriums, stadiums, gymnasiums, concert halls, conference rooms and school furniture. Conclusion: The public schools evaluated present limitations regarding accessibility; the physical barriers erected in the past have not been eliminated and they still represent obstacles to be overcome by students with special needs.

Keywords: Occupational Therapy, Self-help Devices, Architectural Accessibility.

\section{Introdução}

A inclusão social vem sendo pactuada pela união através de diferentes projetos com os estados e municípios, de propostas para a sociedade que englobam mudança de paradigmas e por açóes que envolvem diferentes campos de saberes, levando as profissóes a repensarem suas práticas (LIMA, 2007).

Desde o final da década de 1980 , com a promulgação da Constituição Federal (BRASIL, 2006) o direito de ir e vir, com dignidade e cidadania, usufruindo de todos os recursos oferecidos pela união de forma igualitária é garantia instituída no Brasil. Sobre a educação, é determinado que o Estado, em conjunto com a família, tem o dever de oferecer, a toda população, ensino de qualidade, além de oferecer na própria rede regular de ensino educação especializada e gratuita para todos os alunos com necessidades especiais (BRASIL, 1996, 2006).

Já no cenário mundial, o movimento de inclusão de pessoas com necessidades especiais teve sua base fundamentada na Declaração Mundial sobre a Educação para Todos em 1990 (MAZZARINO; FALKENBACH; RISSI, 2011), que passou a garantir como direito fundamental o acesso à educação apontando também os esforços exigidos para atender as necessidades apresentadas pelos indivíduos (ORGANIZAÇÃO..., 1990). Ampliando o movimento de educaçáo para todos promulga-se em 1994 a Declaração de Salamanca, que reafirma e reconhece a urgência de providenciar o acesso à educação para a população com necessidades especiais dentro da rede regular de ensino (ORGANIZAÇÃO..., 1994).

Em 2000, a Organização das Naçóes Unidas para Educação, Ciência e Cultura (Unesco), em uma avaliação mundial dos progressos alcançados em relação à educação, apontou que, apesar do avanço significativo em alguns países, ainda existiam 113 milhóes de crianças sem acesso ao ensino primário. Nesse contexto, ao convocar os países participantes, dentre eles o Brasil, para o Fórum Mundial sobre Educação em Dakar, publica documento reafirmando a Declaraçáo Mundial de Educação para Todos (ORGANIZAÇÃO...,2000, 2008).

Em 2007, a Convenção sobre os Direitos das Pessoas com Deficiência (BRASIL, 2007) promovida no Brasil reconhece a importância que a acessibilidade representa nesse cenário e pontua a urgência de sua garantia, de forma que aqueles com necessidades especiais possam, por meio da acessibilidade, viver de forma independente, participando assim de variados contextos socioculturais. A partir dessa convenção, ponderou-se a necessidade de identificação e eliminação, por parte dos estados e municípios, das barreiras físicas presentes nos ambientes interno e externo que prejudicam o acesso aos espaços públicos como nos meios de transporte, rodovias e edificações, incluindo as escolas (BRASIL, 2008).

Para Pereira et al. (2011), as barreiras arquitetônicas geram dificuldades e comprometem significativamente o acesso de pessoas a locais e a implantação de políticas para melhorar o conhecimento da sociedade frente às questóes de acessibilidade amplia as possibilidades de acesso do indivíduo a locais e serviços, incluindo-o na diversidade do dia a dia. Segundo a CORDE (BRASIL, 2005) a acessibilidade pressupóe chegar ao entorno, circular, permanecer no ambiente com conforto, utilizar os mobiliários e alcançar produtos e a ausência dela representa discriminação e é passível de punição perante as leis, cabendo consideraçóes sobre o ponto de vista moral e ético (BRASIL, 2007).

$\mathrm{Na}$ rede pública de ensino brasileira, essas questôes também são pontuadas e pode ser percebida uma crescente preocupaçáo acerca da temática, considerando sua relevância para o processo de inclusão de crianças e adolescentes com diferentes necessidades educacionais (AGUIAR; DUARTE, 2005; GOMES; BARBOSA, 2006; COSTA; SILVA; RAMALHO, 2010). 
Assim, políticas específicas de inclusão escolar, como o Programa Escola Acessível, implantado em 2007 como parte do Plano de Desenvolvimento da Educação (PDE), vem sendo desenvolvidas no cenário nacional (BRASIL, 2005) e buscam repassar recursos financeiros para os municípios, de acordo com a quantidade de alunos com necessidades educacionais especiais matriculados na rede pública de ensino. Essa verba é destinada ao cumprimento das normas de acessibilidade, incluindo adequação do espaço físico, aquisição de recursos didáticos e pedagógicos, bem como ampliação de informação e comunicação visual (BRASIL, 2011a, 2011b, 2012, 2013).

E embora a garantia de acesso das pessoas com deficiência ou com mobilidade reduzida aos diversos espaços físicos tenha sido regulamentada há quase dez anos pelo Decreto 5.296, de 2 de dezembro de 2004, açóes efetivas ainda são imperativas. Considerando a acessibilidade como a

[...] condição para utilização, com segurança e autonomia, total ou assistida, dos espaços, mobiliários e equipamentos urbanos, e das edificaçôes, [...] (BRASIL, 2004, Art. 8o., s.p.),

para sua promoçáo é necessário a apropriaçáo, uso prático das normas técnicas de acessibilidade, a exemplo da NBR 9050/04 (ASSOCIAÇÃO..., 2004). Nesse contexto, em 2010 ocorreu uma ação conjunta entre o Laboratório Integrado de Tecnologia Assistiva (LITA/UFTM) pertencente à Universidade Federal do Triângulo Mineiro (UFTM) e a Prefeitura Municipal de Uberaba, para analisar a acessibilidade das escolas públicas municipais da rede e mapear o cenário vigente, para implementação do Programa Escola Acessível do governo federal.

O LITA/UFTM é coordenado por uma docente do Curso de Terapia Ocupacional da UFTM e essencialmente composto por acadêmicos de Terapia Ocupacional. Dentre seus objetivos, esse laboratório realiza avaliaçóes do ambiente físico, buscando aumentar o envolvimento de uma pessoa em diferentes ocupaçóes. Reconhece-se que o envolvimento do aluno acontece em um ambiente físico (ambiente natural e construído) e a acessibilidade desse contexto influencia diretamente sua participação e o desempenho necessários para o aprendizado.

Assim, a partir da parceria entre LITA/UFTM e a prefeitura de Uberaba, com o objetivo de possibilitar amplo acesso ao ambiente físico, a recursos didáticos e pedagógicos, à comunicação e à informação em escolas, a equipe técnica do
LITA desenvolveu para a Secretaria de Educação Especial um relatório técnico contendo sugestôes para efetivação da acessibilidade nas escolas públicas desse município. Nesse relatório, os recursos financeiros foram destinados à adaptação arquitetônica de rampas, banheiros, vias de acesso, salas de atendimento educacional especializado e para implementação de sinalizaçáo e aquisição de cadeiras de rodas e mobiliários acessíveis (UNIVERSIDADE..., 2010).

Desse modo, o presente estudo objetivou descrever a acessibilidade das escolas participantes do Programa Escola Acessível em 2010 e identificar materiais adquiridos, adaptaçóes e reformas implementadas, avaliando se as mudanças atenderam à norma técnica de acessibilidade vigente e estavam em acordo com as propostas recomendadas pela equipe técnica.

\section{Procedimentos metodológicos}

Este estudo exploratório e descritivo de natureza qualiquantitativa foi conduzido em dois momentos. No primeiro foi utilizada como delineamento a pesquisa documental (GIL, 2010), sendo os dados coletados através da análise dos arquivos (Roteiro de avaliaçáo para acessibilidade, elaborado por Calado, em 2006) de 2010 do LITA/UFTM referente às escolas municipais de Uberaba.

No segundo momento foi realizado estudo de campo (SAMPIERI; COLLADO; LÚCIO, 2006; GIL, 2009), com coleta dos dados por entrevista, realizada com diretores das escolas municipais de Uberaba, sobre a efetiva implementação das sugestóes para acessibilidade realizadas em 2010 e preenchimento de nova avaliação por meio do mesmo roteiro utilizado anteriormente.

Esse roteiro de avaliação (CALADO, 2006) contém as variáveis referentes às questôes de acessibilidade de: calçadas, estacionamentos, acessos à edificação, circulação interna, esquadrias, banheiros, vestiários, edificaçóes escolares, piscinas, cinemas (ou teatros, auditórios, estádios, ginásios de esporte, casas de espetáculos, salas de conferência e similares) e mobiliários. Cada um desses itens foi avaliado de acordo com as especificidades técnicas da NBR 9050/04.

Os critérios de inclusão para determinação das escolas participantes deste estudo foram: ser da rede municipal de ensino; ter participado do Programa Escola Acessível em 2010, ter a acessibilidade avaliada pelos pesquisadores do Laboratório Integrado de Tecnologia Assistiva 
(UNIVERSIDADE..., 2010) no mesmo ano e a direção da escola assinar o termo de Consentimento Livre Esclarecido. A pesquisa foi aprovada pelo Comitê de Ética da UFTM (parecer 2298 de 2012).

As variáveis referentes ao perfil das escolas e às questôes de acessibilidade do roteiro de avaliaçáo (CALADO, 2006) foram analisadas através de estatística descritiva (frequência absoluta e relativa). As variáveis qualitativas relativas ao perfil das escolas (localização, número de alunos matriculados, número de alunos com deficiência e tipo de ensino) e às aquisiçóes das sugestóes de acessibilidade feitas a partir do laudo técnico emitido pelo LITA/UFTM (UNIVERSIDADE..., 2010) implementadas foram categorizadas através da técnica de análise de conteúdo (BARDIN, 2010) e descritas em termos de frequência (frequência absoluta e relativa), sendo as categorias temáticas agrupadas da seguinte forma: adequação da sala de atendimento escolar especializado (AEE); adoção de sinalização visual e direcional para a sala do AEE; adequação do banheiro; aquisição de mobiliário acessível; manutenção de rota acessível.

\section{Resultados e discussão}

Os dados foram coletados entre os meses de novembro de 2012 a março de 2013 e nesse período foram identificadas 11 escolas que atendiam aos critérios de inclusão. Apenas uma escola teve substituição da equipe dirigente no período.

As características do perfil das escolas (localização, número de alunos matriculados, tipo de ensino, número total de alunos matriculados por localizaçáo) podem ser observadas na Tabela 1 .

Observa-se que a maioria das escolas está localizada no perímetro urbano $(81,8 \%)$, estando apenas duas $(18,2 \%)$ em zona rural. Juntas, totalizaram 7.310 crianças matriculadas, sendo que, dessas, $10,32 \%$ (754 crianças) estavam matriculadas em escolas da zona rural e 89,68\% (6.556 crianças), em escolas urbanas. Ainda, desse total de crianças matriculadas, apenas $0,62 \%$ (45 estudantes) eram crianças com deficiência, sendo que nas escolas urbanas estavam matriculadas 43 crianças com deficiência e, nas escolas rurais, apenas duas.

Tabela 1. Características do perfil das escolas $(\mathrm{n}=11)$.

\begin{tabular}{|c|c|c|}
\hline Características & $\mathrm{N}^{\mathbf{o}}$ & $\%$ \\
\hline \multicolumn{3}{|l|}{ Localização } \\
\hline Urbana & 9 & 81,8 \\
\hline Rural & 2 & 18,2 \\
\hline
\end{tabular}

\section{Número de alunos matriculados}

100 a 400 alunos

401 a 800 alunos

801 a 1.200 alunos

$\begin{array}{rr}1 & 9,1 \\ 7 & 63,6 \\ 3 & 27,3\end{array}$

\section{Tipo de ensino}

$1^{\circ}$ ao $3^{\circ}$ ano

$1^{\circ}$ ao $4^{\circ}$ ano

$\begin{array}{lr}1 & 9,1 \\ 1 & 9,1 \\ 4 & 36,3 \\ 1 & 9,1 \\ 1 & 9,1 \\ 1 & 9,1 \\ 2 & 18,2\end{array}$

Número total de alunos matriculados (Urbana)

Sem deficiência

$1^{\circ}$ ao $5^{\circ}$ ano

$2^{\circ}$ ao $4^{\circ}$ ano

$2^{\circ}$ ao $5^{\circ}$ ano

$3^{\circ}$ ao $5^{\circ}$ ano

Com deficiência

Número total de alunos matriculados (Rural)

Sem deficiência

Fonte: Departamento de Inclusão e Diversidade da Secretaria de Educação do Município de Uberaba, MG.(PREFEITURA DE UBERABA, 2013). 
No que diz respeito às variáveis (Tabela 2): calçada, circulação interna, esquadrias, banheiros, vestiários, piscina, estacionamento, cinemas (ou teatros, auditórios, estádios, ginásios de esporte, casas de espetáculos, salas de conferência e similares) e mobiliário escolar observou-se que
$100 \%$ das escolas apresentaram problemas em pelo menos $85 \%$ dos itens.

Quanto à variável calçada foram consideradas a circulação, o piso utilizado, as guias rebaixadas, o mobiliário e a vegetação. Em relação à circulação, cinco escolas $(45,4 \%)$ realizaram adaptaçóes, mas

Tabela 2. Condição dos itens de acessibilidade das escolas $(\mathrm{n}=11)$.

\begin{tabular}{|c|c|c|}
\hline Descrição & $\mathbf{N}^{\circ}$ & $\%$ \\
\hline \multicolumn{3}{|l|}{ Calçada } \\
\hline \multicolumn{3}{|l|}{ Circulação } \\
\hline Inadequada & 4 & 36,4 \\
\hline Adequada, realizaram adaptação & 2 & 18,2 \\
\hline Realizaram adaptação, mas inadequada & 5 & 45,4 \\
\hline \multicolumn{3}{|l|}{ Piso } \\
\hline Sinalizado & 0 & 0 \\
\hline Não sinalizado & 11 & 100,0 \\
\hline \multicolumn{3}{|l|}{ Guia rebaixada } \\
\hline Não possuia & 9 & 81,8 \\
\hline Possuia, mas inadequada & 2 & 18,2 \\
\hline \multicolumn{3}{|l|}{ Mobiliário (lixeira, poste e telefone público) } \\
\hline Adequado & 0 & 0 \\
\hline Inadequado & 11 & 100,0 \\
\hline \multicolumn{3}{|l|}{ Vegetação } \\
\hline Não danificava a calçada & 4 & 36,4 \\
\hline Danificava a calçada & 7 & 63,6 \\
\hline \multicolumn{3}{|l|}{ Circulação Interna Horizontal } \\
\hline \multicolumn{3}{|l|}{ Piso } \\
\hline Adequado & 0 & 0 \\
\hline Inadequado & 11 & 100,0 \\
\hline \multicolumn{3}{|l|}{ Grelhas } \\
\hline Adequadas & 0 & 0 \\
\hline Inadequadas & 8 & 72,7 \\
\hline Não possuíam grelhas & 3 & 27,3 \\
\hline \multicolumn{3}{|l|}{ Circulação Interna Vertical } \\
\hline \multicolumn{3}{|l|}{ Rampas e escadas } \\
\hline Adequadas & 0 & 0 \\
\hline Inadequadas & 11 & 100,0 \\
\hline \multicolumn{3}{|l|}{ Esquadrias } \\
\hline Adequadas & 0 & 0 \\
\hline Inadequadas & 11 & 100,0 \\
\hline \multicolumn{3}{|l|}{ Banheiros } \\
\hline Adequados & 0 & 0 \\
\hline Inadequados & 11 & 100,0 \\
\hline \multicolumn{3}{|l|}{ Vestiários } \\
\hline Possuem vestiários & 3 & 27,3 \\
\hline Adequados & 1 & 9,1 \\
\hline Inadequados & 2 & 18,2 \\
\hline Não possuem vestiários & 8 & 72,7 \\
\hline \multicolumn{3}{|l|}{ Piscina } \\
\hline Possuem piscina & 1 & 9,1 \\
\hline Adequada & 0 & 0 \\
\hline Inadequada & 1 & 9,1 \\
\hline Não possuem piscina & 10 & 90,9 \\
\hline
\end{tabular}


Tabela 2. Continuação...

\begin{tabular}{lcc}
\hline \multicolumn{1}{c}{ Descrição } & $\mathbf{N}^{\mathbf{0}}$ & $\%$ \\
\hline Estacionamento & & 0 \\
$\quad$ Adequado & 0 & 100,0 \\
$\quad$ Inadequado & 11 & 9,1 \\
Cinema/Auditório/Outro & 1 & 0 \\
Possuem cinema/auditório/outro & 0 & 9,1 \\
$\quad$ Adequado & 1 & 90,9 \\
$\quad$ Inadequado & 10 & 0 \\
Não possuem cinema/auditório/outro & & 100,0 \\
$\quad \begin{array}{l}\text { Mobiliário Escolar Adaptado } \\
\quad \text { Em sala de aula regular }\end{array}$ & 0 & \\
$\quad$ Em sala de aula AEE & 11 & \\
\hline
\end{tabular}

inadequadas, mantendo desníveis que bloqueavam o curso de pessoas; quatro $(36,4 \%)$ não realizaram quaisquer adaptações; e duas $(18,2 \%)$ apresentaram circulação adaptada e adequada. Nenhuma das escolas apresentou na calçada a sinalização direcional tátil (piso tátil direcional e de alerta). Apenas duas escolas $(18,2 \%)$ têm guias rebaixadas mas implementadas de forma inadequada, visto que uma não possui a faixa de pedestre à frente e $\mathrm{a}$ outra não tem a rampa do lado oposto. $\mathrm{O}$ mobiliário (lixeira, poste e telefone público) não estava locado na faixa adequada em $100 \%$ das escolas. As faixas de divisáo da calçada (faixa livre, faixa de serviço e de mobiliário) não estavam adequadamente dividas em nenhuma das escolas avaliadas, sendo que em $100 \%$ delas a faixa de mobiliário locava-se na faixa livre, que devia ser destinada à circulação de pessoas. Apenas quatro escolas $(36,4 \%)$ não tinham a calçada danificada pela vegetação.

A normativa técnica esclarece que o piso utilizado nas calçadas deve ser firme, regular e estável para não causar trepidação em cadeiras de rodas, carrinhos de bebê ou quaisquer outros dispositivos com rodas (ASSOCIAÇÃO..., 2004). $O$ vão livre indicado para circulação de pedestre deve ser de 1,50 m, sendo aceito no mínimo $1,20 \mathrm{~m}$. Já a altura livre mínima indicada é de 2,10 m. Esses parâmetros sáo indicados para que a calçada consiga acomodar de forma adequada o fluxo de pedestres, levando-se em consideração uma inclinação transversal não superior a $3 \%$ e uma inclinação longitudinal de até $8,33 \%(1 / 12)$. No entanto, as calçadas das escolas avaliadas encontravam-se irregulares, apresentando obstáculos pelo trajeto, com rachaduras e pavimentação quebrada e com desníveis acima de $5 \mathrm{~mm}$, sem a devida adequação com rampas (BRASIL, 2006).

Ainda sobre a normatização para calçadas, a recomendação é que elas devem ter piso tátil direcional quando não existir uma linha guia identificável ou ela apresentar descontinuidade, além de piso tátil de alerta quando a calçada apresentar algum risco à segurança como, por exemplo, um desnível (degrau, rampa ou mudança de direção). Mas nenhuma das escolas avaliadas apresentou piso direcional e/ou piso tátil de alerta, o que tornava a circulação externa inacessível às pessoas com deficiência visual.

Quanto às guias rebaixadas, essas devem ser instaladas junto à travessia de pedestres sinalizada, sendo acompanhadas ou não de semáforos ou faixas (BRASIL, 2005). Quando a calçada não acomodar totalmente a faixa livre e o rebaixamento da calçada, devido à sua largura, o rebaixamento deve ser feito em toda a sua extensão, apresentando rampas laterais com inclinação igual ou inferior a 8,33\% (ASSOCIAÇÃO..., 2004).

Além dessas diretrizes, as guias rebaixadas devem apresentar piso tátil de alerta, devido à mudança do nível da faixa transitável. Contudo, em nenhuma das escolas foi identificada guia rebaixada com inclinação adequada. Todas ultrapassavam os $8,33 \%$ estabelecidos pela NBR 9050/04 bem como não tinham o piso tátil de alerta instalado adequadamente. Essa situação constitui fator agravante à segurança dos pedestres da via. Quando essas mesmas escolas tinham guia rebaixada, ainda que inacessível, não se apresentava guia correspondente no lado oposto, o que impossibilitava, então, o acesso dos estudantes à outra calçada. Segundo a NBR 9050/04, as guias também devem apresentar abas laterais mínimas de $0,50 \mathrm{~m}$, atendendo a inclinação máxima de $10 \%$, excluindo-se os casos em que existem obstáculos na superfície imediatamente ao lado da guia. Nesses casos deve então ser garantida faixa livre recomendável de $1,50 \mathrm{~m}$ ou, no mínimo, de $1,20 \mathrm{~m}$ (ASSOCIAÇÃO..., 2004). 
Já o mobiliário urbano deve ser implantado nas calçadas em faixa específica, mediante autorização de órgão público, e não deve transpor-se para a faixa livre, onde os pedestres circulam, e nem para a faixa de acesso que permite o ingresso às edificações (BRASIL, 2006). Porém, nas escolas analisadas havia orelhóes, postes e vegetação impedindo a livre circulação na faixa destinada apenas aos pedestres, o que os tornava mais um obstáculo no percurso de acesso às escolas.

Referente à circulação interna, dividiu-se a análise didaticamente entre circulação interna horizontal $(\mathrm{CIH})$ e circulação interna vertical (CIV). Em CIH foram avaliados o piso e as grelhas e em CIV rampas, escadas, elevadores ou plataformas elevatórias. Na circulação interna horizontal todas as escolas apresentaram inadequaçóes no piso e não possuíam sinalização tátil horizontal. Em relação às grelhas, destinadas à canalização de água pluvial, oito escolas $(72,8 \%)$ tinham grelhas inadequadas e as demais não apresentavam grelhas em seu projeto arquitetônico. Quanto à CIV, quatro $(36,4 \%)$ escolas eram edificadas em dois andares e sete (63,6\%), em um único pavimento. Das escolas que possuíam dois andares, uma $(9,1 \%)$ foi edificada em terreno sem desnível e três (27,3\%), edificadas em dois pavimentos, em terreno com desnível. Entre as escolas com edificação em apenas um andar, três (27,3\%) não apresentavam desnível do terreno e quatro $(36,4)$ foram construídas em terrenos com diferença de nível, sendo que em duas, essa diferença é de no mínimo $2,50 \mathrm{~m}$.

Para circulação interna, as diretrizes de acessibilidade apontam a necessidade de se implantar uma rota acessível interligando todos os acessos escolares, como áreas administrativas, salas de aula, área de alimentação e recreação, banheiros, quadra de esportes, biblioteca, laboratórios e demais espaços educacionais (CALADO, 2006). Todas as escolas apresentaram corredores (ou espaços) iguais ou maiores do que o estabelecido pelas normas para a circulaçáo das pessoas, porém muitos deles apresentaram grelhas fora do estabelecido, não estando fixadas e embutidas no piso. $\mathrm{O}$ piso se mostrava irregular, com rachaduras e, em alguns casos, com buracos que causavam trepidaçóes durante locomoção em cadeira de rodas.

Todas as escolas apresentaram rampas inadequadas, de acordo com a NBR 9050/04. Essas devem ter inclinação máxima de 8,33\% e a sua largura deve ser estabelecida de acordo com o fluxo de pessoas. Além desses parâmetros, quando a inclinação é maior que 6,25\% a rampa deve comportar uma área para descanso
(ASSOCIAÇÃO..., 2004). Mesmo nas escolas com rampas que possuíam inclinação adequada, essas não apresentam guarda-corpos nem corrimãos com prolongamento de $30 \mathrm{~cm}$ antes e depois do início da rampa, e nenhuma tinha piso tátil de alerta no início ou no fim das rampas. Nas escolas que as apresentaram, as escadas estavam inadequadas em relaçáo ao tamanho do espelho ou à largura do piso, maiores do que o estabelecido pela norma técnica vigente, sem corrimãos e guarda-corpos ou pisos táteis de alerta, o que constituía uma barreira para pessoas com deficiência sensorial, por exemplo. Nenhuma escola tinha plataforma elevatória ou elevador.

Com relação às esquadrias, todas as escolas se mostraram inadequadas, não atendendo a largura mínima do vão livre, preconizado em $0,80 \mathrm{~cm}$. Os banheiros considerados acessíveis no momento da avaliaçáo pelos diretores estavam sendo utilizados como depósito para material de limpeza, livros ou simplesmente permaneciam trancados, não sendo possível o seu uso pelos alunos, a não ser que solicitado previamente. Já os vestiários, presentes em três $(27,3)$ escolas, estavam um $(9,1 \%)$ dentro dos parâmetros exigidos e dois $(18,2 \%)$ em estado de abandono. Apenas uma escola apresentava piscina e essa não possuía garantia de acesso à água por degraus, rampas submersas, bancos de transferência ou plataforma para acesso de pessoas com deficiência. Também não possuía barras de apoio em suas bordas internas, conforme recomenda a NBR 9050/04 (ASSOCIAÇÃO..., 2004).

Um banheiro acessível deve conter piso antiderrapante, portas de acesso ao banheiro e ao boxe do sanitário largas, pisos, paredes e equipamentos com cores contrastantes e acessórios ao alcance de todos (BRASIL, 2006). Já Calado (2006) acrescenta que o banheiro e o boxe devem ter espaço suficiente para que a pessoa consiga circular e realizar as manobras necessárias na cadeira de rodas, para se transferir para o vaso sanitário. A altura do lavatório deve estar adequada, permitindo a aproximação da cadeira de rodas, assim como as descargas e torneiras devem ser de fácil manuseio, sendo recomendado o tipo alavanca ou pressão. $\mathrm{O}$ banheiro também deve apresentar barras na porta, para facilitar seu fechamento, e também na parede ao lado e ao fundo do vaso sanitário, como apoios para a transferência do indivíduo em cadeira de rodas (DISCHINGER; ELY; BORGES, 2009).

Quanto ao estacionamento, em nenhuma das escolas visitadas eles estavam adequados, com ausência de vagas reservadas a pessoas com deficiência, como estabelecido pela NBR 9050/04 
04 (ASSOCIAÇÃO...., 2004). A quantidade exigida para escolas que contam entre 11 a 100 vagas de estacionamento é de uma vaga reservada para pessoas com deficiência (CALADO, 2006). Além disso, as escolas não apresentavam sinalização vertical e/ou horizontal demarcando a vaga reservada para esses indivíduos.

Da amostra, apenas uma escola $(9,1 \%)$ tem auditório de eventos, sem quaisquer itens referentes à acessibilidade como, por exemplo, sinalização visual, cadeira especial para obesos ou lugar reservado para pessoa em cadeira de rodas.

Com relação ao mobiliário de sala de aula (mesa e cadeira escolar), nenhuma escola tinha o conjunto de mesa e cadeira adaptadas para alunos com deficiência em sala de aula regular, com a inclusão desse item na sala de aula do AEE em todas as 11 escolas visitadas.

$\mathrm{Na}$ identificação dos materiais adquiridos, adaptaçôes e reformas implementadas no período avaliado se constatou que oito $(72,7 \%)$ escolas realizaram adequação de sala de atendimento escolar especializado (AEE); nenhuma implementou adoção de sinalização visual e direcional de rota acessível para a sala do AEE; sete $(63,7 \%)$ escolas adequaram o banheiro. Todas as escolas adquiriram mobiliário acessível (conjunto de mesa e cadeira) para a sala de aula do AEE (Tabela 3).

$\mathrm{Na}$ avaliação das mudanças, ponderando-se se essas atenderam a norma técnica de acessibilidade vigente, aponta-se que nenhuma das escolas apresentou as melhorias em consonância com a norma técnica. Como exemplo, na circulação interna horizontal, duas $(18,2 \%)$ escolas haviam realizado adequações no piso, porém não tinham implementado piso tátil direcional e de alerta na rota de acesso. Em relação à circulação interna vertical, em sete $(63,7 \%)$ escolas as rampas edificadas como rota alternativa às escadas ainda apresentavam irregularidades, como ausência de piso tátil de alerta, de corrimãos e de guarda-corpos.

Apenas duas $(18,2 \%)$ escolas realizaram adequação das esquadrias das portas, adotando medidas que apresentavam vão livre de $0,80 \mathrm{~m}$. Já com relação aos banheiros, apesar de nove $(81,9 \%)$ terem sido reformados, ainda se encontravam inadequados por náo atenderem todas as especificações da norma técnica.

Quando se analisa o mobiliário de sala de aula (mesa e cadeira escolar), dez escolas $(90,9 \%)$ adquiriram pelo menos dois conjuntos de mesa e cadeira adaptados porém, dessas, três $(27,3 \%)$ adquiriram o conjunto de mesa e cadeira inadequado, uma vez que as mesas náo apresentavam o recorte para aproximação da cadeira de rodas.

Em uma última análise o Programa Escola Acessível é voltado para escolas públicas de ensino regular e objetiva fomentar a acessibilidade no contexto físico delas, assim como fornecer acesso a recursos didáticos e pedagógicos. A verba destina-se à adequação dos espaços edificados, com subsídio para ajuste de rampas, banheiros, rotas de acesso, aquisição de corrimãos em rampas e escadas e instalação de sinalização visual, tátil e sonora; como também se destina à aquisiçấo de equipamentos e materiais de tecnologia assistiva.

Das açôes implementadas no período em estudo é possível identificar adequação do espaço físico e aquisição de materiais de tecnologia assistiva. No entanto, as especificações necessárias para a efetivação da acessibilidade não foram cumpridas,

Tabela 3. Materiais adquiridos, adaptações e reformas implementadas nas escolas ( $\mathrm{n}=11)$.

\begin{tabular}{lcc}
\hline \multicolumn{1}{c}{ Descrição } & $\mathbf{N}^{\mathbf{0}}$ & $\%$ \\
\hline Adequação em salas de AEE & & 72,7 \\
Implementada & 8 & 27,3 \\
Não implementada & 3 & \\
& & 0 \\
Adoção de sinalização visual e direcional & 0 & 100,0 \\
Implementada & 11 & \\
Não implementada & & 63,7 \\
Adequação do banheiro & 7 & 27,3 \\
Implementada & $4(36,4)$ & 100,0 \\
Não implementada & & 0 \\
Aquisição de mobiliário acessível & 11 & 0 \\
Implementada & 0 & \\
Não implementada &
\end{tabular}


seja por falta de conhecimento dos gestores, restrição do recurso financeiro, escassez ou ausência de mão de obra qualificada e/ou insuficiência de orientação qualificada.

Todas as escolas realizaram pelo menos uma implementação das propostas recomendadas pela equipe técnica que vai ao encontro das diretrizes do programa. E quatro escolas fizeram aquisiçôes que não foram sugeridas no relatório da equipe do LITA/UFTM, adquirindo material desportivo adaptado para o deficiente visual, cadeira de banho e cadeira de rodas. Essas aquisiçóes foram ao encontro das necessidades de cada uma dessas escolas, talvez justificadas pela demanda do Programa Escola Acessível e/ou tempo de uso do recurso disponibilizado; questốes que merecem novas investigaçóes em outros estudos.

\section{Conclusão}

De forma resumida, esta pesquisa possibilitou uma visão inicial de como está o cenário da acessibilidade nas escolas do município de Uberaba que fazem parte do Programa Escola Acessível. Esse cenário indica que são necessárias medidas mais efetivas para concretizar a meta estabelecida pela UNESCO, acordada pelo governo brasileiro em 2007 na Convenção sobre os Direitos das Pessoas com Deficiência, e sugere estudos que analisem o processo de implementaçáo das açôes voltadas para acessibilidade no sentido de identificar as dificuldades práticas encontradas pelos dirigentes das escolas nesse processo.

A partir da avaliação realizada, os resultados indicam que as escolas públicas municipais de Uberaba participantes do Programa Escola Acessível em 2010 não estão acessíveis em todos os aspectos analisados. As barreiras físicas no passado edificadas não foram realmente eliminadas e ainda são obstáculos a serem transpostos pelos alunos com necessidades especiais, apesar das açôes implementadas pelos gestores de cada escola.

E, com o material adquirido, levantamento das reformas e adaptaçóes realizadas foi possível identificar que os diretores conseguiram efetivar pelo menos uma das sugestôes (por exemplo, aquisição de mobiliário acessível; adequação arquitetônica de espaço físico reservado a sala de recursos multifuncionais; adequação de sanitários para pessoas com deficiência; adequação de rota acessível da entrada da escola até a sala de recursos multifuncionais ou aquisiçáo de material desportivo acessível) feitas pela equipe técnica do LITA/UFTM, entendendo que as açóes foram ao encontro das demandas apontadas para acessibilidade. Ressalta-se que em algumas escolas houve ações em prol da acessibilidade que foram implementadas fora da proposta sugerida pelo relatório técnico, seguindo diretrizes da própria administração do colégio.

Também foi constatado que todas as alteraçôes implementadas pelos dirigentes das escolas, tanto as que foram sugeridas quanto as que náo foram recomendadas, não atendiam ao que é estabelecido pela NBR 9050/04, que é o eixo norteador de acessibilidade no Brasil.

Os dirigentes escolares manifestaram real intenção de mudança e melhoria do ambiente físico, mas percebeu-se que a ausência de informação adequada sobre a temática bem como sobre a normativa de acessibilidade constituiram-se como barreiras nesse processo de alteração do ambiente físico. Apesar do investimento financeiro por parte do governo, existe ainda uma limitação para a efetiva implementação da acessibilidade nesses espaços. Essa dificuldade pode ser atribuída à ausência de pessoal qualificado para implementar a adaptação e/ou reforma, bem como para acompanhar as ações, monitorando as alternativas de acordo com a norma técnica de acessibilidade.

\section{Referências}

AGUIAR, J. S.; DUARTE, E. Educação inclusiva: um estudo na área da educação física. Revista Brasileira de Educação Especial, Piracicaba, v. 11, n. 2, p. 223-240, maio/ago. 2005. http://dx.doi.org/10.1590/ S1413-65382005000200005

ASSOCIAÇÃO BRASILEIRA DE NORMAS TÉCNICAS - ABNT. NBR 9050: acessibilidade e edificaçôes, mobiliário, espaços e equipamentos urbanos. Brasília, 2004.

BARDIN, L. Análise de conteúdo. Tradução Luís Antero Reto, Augusto Pinheiro. Lisboa: Ediçôes 70, 2010.

BRASIL. Constituição (1988). Constituição da República Federativa do Brasil: texto promulgado em 5 de outubro de 1988, com as alteraçôes adotadas pelas Emendas Constitucionais $n^{\circ} 1 / 92$ a 52/2006 e pelas Emendas Constitucionais de Revisão no 1 a 6/94. Brasília: Senado Federal, Subsecretaria de Ediçóes Técnicas, 2006.

BRASIL. Lei no 9.394, de 20 de dezembro de 1996. Estabelece as diretrizes e bases da educação nacional. Diário Oficial da República Federativa do Brasil, Poder Executivo, Brasília, DF, 20 dez. 1996. Disponível em: <http://www.planalto.gov.br/ccivil_03/leis/L9394.htm>. Acesso em: 12 mar. 2013

BRASIL. Decreto No 5.296, de 2 de dezembro de 2004. Regulamenta as Leis nos 10.048 , de 8 de novembro de 2000 , que dá prioridade de atendimento às pessoas 
que especifica, e 10.098, de 19 de dezembro de 2000, que estabelece normas gerais e critérios básicos para a promoção da acessibilidade das pessoas portadoras de deficiência ou com mobilidade reduzida, e dá outras providências. Diário Oficial da República Federativa do Brasil, Brasília, DF, 3 dez. 2004. Disponível em: <http:// www.planalto.gov.br/ccivil_03/_ato2004-2006/2004/ decreto/d5296.htm>. Acesso em: 15 out. 2013.

BRASIL. Secretaria Especial dos Direitos Humanos. Coordenadoria Nacional para a Integraçáo da Pessoa Portadora de Deficiência. Acessibilidade. Brasília: Secretaria Especial dos Direitos Humanos, 2005.

BRASIL. Ministério da Educação. Secretaria de Educação Especial. Documento Subsidiário à Política de Inclusão. Brasília, 2005.

BRASIL. Ministério do Turismo. Secretaria Nacional de Políticas de Turismo. Turismo e acessibilidade: manual de orientaçáo. Brasília: Ministério do Turismo, 2006.

BRASIL. Secretaria Especial dos Direitos Humano. Coordenadoria Nacional para Integração da Pessoa Portadora de Deficiência. Convenção sobre os Direitos das Pessoas com Deficiência: protocolo facultativo à convençáo sobre os direitos das pessoas com deficiência. Brasília, DF, 2007.

BRASIL. Ministério das Cidades. Brasil Acessível - Programa brasileiro de acessibilidade urbana. 2. ed. Brasília, DF: Secretaria Nacional de Transporte e da Mobilidade Urbana, 2008. (Construindo a cidade acessível, Caderno 2).

BRASIL. Decreto no 7.611, de 17 de novembro de 2011. Dispóe sobre a educação especial, o atendimento educacional especializado e dá outras providências. Diário Oficial da República Federativa do Brasil, Poder Executivo, Brasília, DF, 17 nov. 2011a. Disponível em: <http://www.planalto.gov.br/ccivil_03/_Ato20112014/2011/Decreto/D7611.htm>. Acesso em: 13 mar. 2013.

BRASIL. Ministério da Educação. Programa escola acessivel: manual do programa escola acessível. Brasília, DF, 2011b.

BRASIL. Ministério da Educação. Fundo Nacional de Desenvolvimento da Educaçáo. Conselho Deliberativo. Resolução no 27 de 27 de julho de 2012. Dispóe sobre a destinação de recursos financeiros, nos moldes e sob a égide da Resoluçáo no 7, de 12 de abril de 2012, a escolas públicas municipais, estaduais e do Distrito Federal da educaçáo básica, com matrículas de alunos público alvo da educaçấo especial em classes comuns do ensino regular, que tenham sido contempladas com salas de recursos multifuncionais em 2010 e 2011 e integrarão o Programa Escola Acessível em 2012. Diário Oficial da República Federativa do Brasil, Poder Executivo, Brasília, DF, 30 jul. 2012. Seção 1.

BRASIL. Ministério da Educaçáo. Secretaria de Educação Continuada, Alfabetização, Diversidade e Inclusão. Programas e açôes. Brasília, 2013. Disponível em: $<$ http://portal.mec.gov.br/index.php?option $=\mathrm{com}_{-}$ content\&view=article\&id $=17428 \&$ Itemid $=817>$. Acesso em: 29 jan. 2013.
CALADO, G. C. Acessibilidade no ambiente escolar: reflexóes com base no estudo de duas escolas municipais de Natal-RN. 2006. 191 f. Dissertação (Mestrado em Arquitetura e Urbanismo)-Universidade Federal do Rio Grande do Norte, Natal, 2006.

COSTA, L. F.; SILVA, A. C. P.; RAMALHO, F. A. Para além dos estudos de uso da informação arquivística: a questão da acessibilidade. Revista Ciência da Informação, Brasília, DF, v. 39 n. 2, p. 129-143, maio/ago., 2010.

DISCHINGER, M.; ELY, V. H. M. B.; BORGES, M. M. F. C. Manual de acessibilidade espacial para escolas: o direito a escola acessível. Brasília, DF: Ministério da Educação, Secretaria de Educação Especial, 2009.

GIL, A. C. Como elaborar projetos de pesquisa. 5. ed. São Paulo: Atlas, 2010.

GIL, A. C. Estudo de caso. São Paulo: Atlas, 2009.

GOMES, C.; BARBOSA, A. J. G. Inclusão escolar do portador de paralisia cerebral: atitudes de professores do ensino fundamental. Revista Brasileira de Educação do Esporte, Piracicaba, v. 12, n. 1, p. 85-100, jan./abr. 2006. http://dx.doi.org/10.1590/S1413-65382006000100007

LIMA, N. M. Pessoa portadora de deficiência: legislaçâo federal básica. Brasília, DF: Secretaria Estadual de Direitos Humanos, Coordenadoria Nacional para Integração da Pessoa Portadora de Deficiência, 2007.

MAZZARINO, J. M.; FALKENBACH, A.; RISSI, S. Acessibilidade e inclusão de uma aluna com deficiência visual na escola e na educação física. Revista Brasileira de Ciências do Esporte, Florianópolis, v. 33, n. 1, p. 87-102, jan./mar. 2011. http://dx.doi.org/10.1590/ S0101-32892011000100006

ORG A N IZ AÇÃ O D A S N AÇÓ E S UNIDAS - UNESCO. Declaração de Salamanca sobre princípios, politica e práticas na área das necessidades educativas especiais. Salamanca, 1994.

ORGA N I Z AÇÃO DAS NAÇÕ E S UNIDAS - UNESCO. Declaração Mundial sobre educação para todos: satisfação das necessidades básicas de aprendizagem. Jomtien, 1990.

ORGANIZAÇÃ O DAS NAÇÓES UNIDAS - UNESCO. Educação para todos: o compromisso de Dakar. Dakar, 2000.

ORGA N IZ AÇÃO DAS NAÇÓES UNIDAS - UNESCO. Relatório de monitoramento de educação para todos Brasil 2008: educação para todos em 2015, alcançaremos a meta? Brasília, DF, 2008.

PEREIRA, L. M. F. et al. Acessibilidade e crianças com paralisia cerebral: a visão do cuidador primário. Revista Fisioterapia em Movimento, Curitiba, v. 24, n. 2, p. 299-306, abr./jun. 2011.

SAMPIERI, R. H.; COLLADO, C. F.; LUCIO, P. B. Metodologia de pesquisa. São Paulo: Mc Graw Hill, 2006. UNIVERSIDADE FEDERAL DO TRIÂNGULO MINEIRO - UFTM. Laboratório Integrado de Tecnologia Assistiva - LITA. Relatório de acessibilidade das escolas municipais de Uberaba contempladas pelo Programa de Implementação de Salas de Recursos Multifuncionais MEC/SEESP nos anos 2005 a 2008. Uberaba: UFMT, 2010. Relatório técnico nấo publicado. 


\section{Contribuição dos Autores}

Victor Ruan Carvalho Soares: elaborou o projeto de pesquisa, coletou e analisou os dados, e redigiu o texto. Alessandra Cavalcanti: orientou a concepção do projeto de pesquisa, auxiliou na coleta dos dados, orientou análise dos dados e redação do texto. Fabiana Caetano Martins Silva e Andrea Ruzzi-Pereira: revisão do texto. Todos os autores aprovaram a versão final do artigo.

\section{Notas}

${ }^{1}$ Resultado do Trabalho de Conclusão de Curso (TCC) do Curso de Terapia Ocupacional da Universidade Federal do Triângulo Mineiro (UFTM) - aprovado pelo Comitê de Ética da UFTM de acordo com o parecer no 2298/2012. 